Abstracta Iranica Abstracta Iranica

Revue bibliographique pour le domaine irano-aryen

Volume 30 | 2010

Comptes rendus des publications de 2007

\title{
After Alexander. Central Asia before Islam. Oxford, Oxford University Press, 2007. (Proceedings of the British Academy, 133), xvi-514 p.
}

Étienne de La Vaissière

(2) OpenEdition

Journals

Édition électronique

URL : http://journals.openedition.org/abstractairanica/37588

DOI : 10.4000/abstractairanica.37588

ISSN : 1961-960X

Éditeur :

CNRS (UMR 7528 Mondes iraniens et indiens), Éditions de l'IFRI

Édition imprimée

Date de publication : 8 avril 2010

ISSN : 0240-8910

Référence électronique

Étienne de La Vaissière, "After Alexander. Central Asia before Islam. Oxford, Oxford University Press,

2007. (Proceedings of the British Academy, 133), xvi-514 p. », Abstracta Iranica [En ligne], Volume 30 ।

2010, document 41, mis en ligne le 08 avril 2010, consulté le 04 octobre 2020. URL : http://

journals.openedition.org/abstractairanica/37588; DOI : https://doi.org/10.4000/abstractairanica.

37588

Ce document a été généré automatiquement le 4 octobre 2020.

Tous droits réservés 


\title{
After Alexander. Central Asia before Islam. Oxford, Oxford University Press, 2007. (Proceedings of the British Academy, 133), xvi-514 p.
}

\author{
Étienne de La Vaissière
}

1 Outre les articles de Rapin, Grenet et al., Smirnova, Semyenov, Betts et Yagodin, Invernizzi, Zavyalov dont il est rendu compte séparément, ce recueil, fort riche comprend, parmi 23 communications :

2 - K. Abdullaev, « Nomad Migration in Central Asia », pp. 73-98, traite des migrations au II ${ }^{\mathrm{e}}$ siècle av. n.è. et présente notamment l'important site de Kala-i Zakhoki Maron.

3 - S. Stride, " Regions and Territories in Southern Central Asia: What the Surkhan Darya Province tell us about Bactria», pp. 99-117, montre par une analyse des territoires combien Termez est une cité créée par des pouvoirs étatiques pour les besoins du commerce et de l'armée, tandis que Chaganyan isolée au nord de sa vallée est un exemple d'une entité autonome mais aux moyens limités.

4 - P. Leriche, «Bactria, Land of a Thousand Cities", pp. 121-153, montre combien l'urbanisation de la Bactriane doit peu aux Grecs.

5 - P. Leriche, Sh. Pidaev, "Termez In antiquity », pp. 179-211, les AA. font le bilan des fouilles portant sur la période ancienne de l'histoire de la ville proprement dite.

6 - G. A. Koshelenko, «The Fortifications at Gobekly-tepe », pp. 269-283, présente le seul site de l'oasis de Merv des époques parthe et sassanide qui puisse fournir un parallèle à l'étude des fortifications de Gyaur-kala.

7 - O. Lecomte, "Gorgân and Dehistan: The North-East Frontier of the Iranian Empire ", pp. 295-312, donne une présentation globale de l'histoire archéologique de cette région et du site de Geoktchik tepe. 
8 - M. Rahbar, «A Tower of Silence of the Sasanian Period at Bandiyan: some Observations about Dakhmas in Zoroastrian Religion ", pp. 455-473, traite des modes d'inhumation sassanides.

9 Sur le site voir Ph. Gignoux dans St. Ir. 37.22008 pp. 163-174.

INDEX

Thèmes : 3.1. Est de l'Iran

\section{AUTEURS}

ÉTIENNE DE LA VAISSIÈRE

EPHE - Paris 